\title{
Prevalence of Hyperemesis Gravidarum and Associated Factors in Arba Minch General Hospital, Gamo Gofa Zone, Southern Ethiopia
}

\section{Gemechu Kejela $^{1^{*}}$, Shimelis Getu ${ }^{2}$, Tadla Gebretsdik ${ }^{2}$ and Tesfaye Wendimagegn ${ }^{2}$}

${ }^{1}$ Department of Public Health, College of Medicine and Health Sciences, Arba Minch University, Arba Minch, Ethiopia

${ }^{2}$ School of Medicine, College of Medicine and Health Sciences, Arba Minch University, Arba Minch, Ethiopia

*Corresponding author: Kejela G, Department of Public Health, College of Medicine and Health Sciences, Arba Minch University, Arba Minch, Ethiopia, E-mail: gemechukejela86@gmail.com

Received date: January 02, 2018; Accepted date: January 30, 2018; Published date: February 05, 2018

Copyright: $\odot 2018$ Kejela G, et al. This is an open-access article distributed under the terms of the Creative Commons Attribution License, which permits unrestricted use, distribution, and reproduction in any medium, provided the original author and source are credited.

\begin{abstract}
Background: Nausea and vomiting of pregnancy (NVP) are common symptoms experienced during pregnancy. Both mild and severe symptoms can have significant morbidities and socioeconomic impact. Despite its frequency and associated distress, its exact cause is unknown. No significant study was done addressing this particular important issue in our country and our globe as well and this study will serve as a bench mark for future work on the topic.
\end{abstract}

Objective: To assess prevalence of hyperemesis gravidarum and associated factors in women attending antenatal care in Arba Minch general hospital.

Methods and materials: A descriptive facility based cross-sectional study was done in Arbaminch general hospital. Semi-structured questionnaires were administered to a sample of 183 admitted pregnant women. Descriptive statistic was used to summarize data. SPSS 20 is used to analyse the data.

Results: The prevalence of hyperemesis gravidarum was $8.2 \%$. It was found out that $80 \%$ had symptoms in the $1^{\text {st }}$ trimester, $2.1 \%$ continue to have it after $1^{\text {st }}$ trimester, and $85 \%$ were triggered by smell and taste.

Conclusions and recommendations: Prevalence and associated factors of hyperemesis gravidarum in this study are similar to other studies. Sensory stimuli were major trigger of symptoms.

Keywords: Hyperemesis gravidarum; Arba Minch; General hospital

\section{Introduction}

Nausea and vomiting is a common experience for women in pregnancy (NVP). Symptoms are usually limited to the first trimester, but can continue throughout pregnancy and even persist until birth [1]. The severity of nausea and vomiting may affect the physical and emotional health of the pregnant women, family, social and occupational functioning [2], the stages of maternal role attainment, and even outcomes for the unborn child like low birth weight [3].

The exact etiologic factor for nausea and vomiting is unknown, but it is widely agreed that it is a multifactorial condition with genetic, physiological, behavioural, dietary, social, and psychological contributing determinants [4]. However, the reports regarding these determinants continue to be contradictory and are often restricted to either the first trimester of pregnancy or hyperemesis gravid arum (HEG), the most severe form of NVP [5]. The overall clinical symptoms are believed to be highly variable and tend to be affected by the age, marital status, place of residence, race/ethnicity, cultural, social, and educational status of the individual [6].

The literatures has shown that worry, stress, anxiety, depression and unintended pregnancy as well as cigarette, alcohol and drug use can all have deleterious effects on the health of the foetus, the baby, and the mother [7].

According to the Hyperemesis Education and Research Foundation, conservative estimates indicate that, HEG can cost a minimum of \$200 million annually in in-house hospitalizations in the United States [8]. In a related economic analysis, Piwko et al. projected that the United States spends nearly $\$ 2$ billion in costs attributed to pregnancy-related nausea and vomiting; $60 \%$ of this expenditure is result of direct costs (e.g., drugs, hospital admission), and $40 \%$ is a result of indirect costs (e.g., time lost from work) [9].

In Germany, in 2005, the yearly cost of hospital admittances alone for hyperemesis gravidarum was about 28 million Euros, and the cost of lost working hours and outpatient treatment is not even included in this amount [10].

There is increasing evidence that NVP has emerged as a common phenomenon among urbanized human population with increased genetic heterogeneity as its occurrence is rare among foraging population such as the Bushmen of South Western Africa and the Amazonian Amerindian tribes with well documented genetic homogeneity [11].

Apart from the ethnic difference in the occurrence of NVP, some anthropometric and demographic factors have also been associated with NVP as studies have reported association between maternal age, 
body weight, parity, sex of foetus, family history and experience in previous pregnancy as factors which bears increased risk of developing severe NVP [12-15].

HEG can be associated with serious maternal and foetal morbidity such as Wernicke's encephalopathy, foetal growth restriction, and even maternal and foetal death [16-19]. In some instances long-lasting, very intensive vomiting, might in rare cases lead to esophageal mucosal injury/tear (a Mallory-Weiss syndrome), rupture of oesophagus or spleen, choroid bleedings, transient hypothyroxinemia, pneumothorax as well as neurological complications such as myelinolysis of the cerebellum or Wernicke encephalopathy caused by lack of vitamin B1 [16].

Prim gravidity, null parity, excessive salivation and food aversion were significantly associated with nausea and vomiting during pregnancy [20-24]. Significant associations were also observed between admission for severity and being unmarried, loss to work, affected relationship, more frequent vomiting, and early onset of symptoms. Severe frequency of vomiting was a major factor associated with admission for severity and loss to work [25].

In our country, the study conducted in Addis Ababa showed that, the prevalence of nausea and vomiting during pregnancy was $74.5 \%$, with $4.4 \%$ being admitted for severe symptoms. It also found out that $91 \%$ had symptoms in the $1^{\text {st }}$ trimester, $2.1 \%$ after mid pregnancy, and $85 \%$ were triggered by smell and taste.

Despite the presence of a problem and its severity in Ethiopia, there is scarcity of studies that show the magnitude and factors that associated with the problem. So, the main aim of this study was to assess the prevalence of hyperemesis gravidarum and associated factors in women attending Arba Minch general hospital. The study helps all women affected by the problem, health professionals, researchers, government bodies and NGOs to solve the problem. In addition, it provides base line information for further studies to be carried out and also will add a bit to the literature pool of the library [26-28].

\section{Methods}

Institution based cross sectional study was conducted in Arba Minch general hospital from January 21-January 30, 2016. The hospital is found in Arba Minch town, the capital city of Gamo Gofa zone. Arbaminch is located at $505 \mathrm{~km}$ from Addis Ababa, the capital city of the country. The town has 1 zonal hospital and 2 governmental health centres and 69 private health institutions. According to the figure from Central Statistical Agency 2007, the town has a total population of 90,000, of which reproductive age women accounted for 42,792.

All pregnant women admitted to gynaecology/obstetric ward during the study period were the source population and all women admitted to gynaecology/obstetric ward during the study period, which fulfil the inclusion criteria were the study population.

The sample size was calculated using the single population proportion formula by using the following assumption; prevalence of hyperemesis gravid arum of $4.4 \%$ from the study conducted in Addis Ababa teaching hospitals, the margin of error of $3 \%$ and $95 \%$ confidence interval. The final calculated sample size was 183. Systematic sampling method was used to interview admitted pregnant mothers to the hospital.
The dependent variable for this study was hyperemesis Gravid arum, which is defined as severe (un able to tolerate per mouth feeding) form of nausea and vomiting in pregnant mothers characterized by significant weight loss $(5 \%$ weight loss from pre pregnancy) and ketonuria $[10,16]$. For data collection, 5 midwifery nurses were recruited as data collectors and $3 \mathrm{MPH}$ professionals were recruited as supervisors. Data was collected by interviewing admitted pregnant women using the structured questionnaire after letter of permission was taken from Arba Minch University ethical review board.

To control the quality of data, before data collection, training was given for data collectors and supervisors. Pre-test was conducted on $5 \%$ of the sample and then possible adjustments or modifications were made based on the result of pre-test. In addition close supervision was conducted by supervisors.

To know the association between variables univariate and bivariate analysis was done using binary logistic regression. Finally variables with P-value of $<0.05$ will be considered as statistically significant association with the outcome variable.

\section{Results}

\section{Socio-demographic characteristics}

The age distribution of the study subjects ranged from $18-45$ years, $95(51.9 \%)$ were between the ages of $25-34$ years with a mean age of $28.04 \pm 6.14$ years. Most were Gamo 105 (57.4\%) in ethnicity, living together $169(92.3 \%)$, completed secondary education 121 (66.1\%); employed 89 (48.6\%) (Table 1).

\begin{tabular}{|c|c|c|}
\hline Socio-demographic variable & Frequency & Percentage \\
\hline \multicolumn{3}{|l|}{ Age in year } \\
\hline$\leq 18$ & 9 & 4.9 \\
\hline $19-24$ & 50 & 27.3 \\
\hline $25-34$ & 95 & 51.9 \\
\hline$\geq 35$ & 29 & 15.8 \\
\hline \multicolumn{3}{|l|}{ Place of residence } \\
\hline Rural & 62 & 33.9 \\
\hline Urban & 121 & 66.1 \\
\hline \multicolumn{3}{|l|}{ Occupation } \\
\hline Farmer & 50 & 27.3 \\
\hline G/ment employee & 45 & 24.6 \\
\hline Self-employee & 44 & 24 \\
\hline Student & 18 & 9.8 \\
\hline Others & 26 & 14.2 \\
\hline \multicolumn{3}{|l|}{ Educational status } \\
\hline Illiterate & 40 & 21.9 \\
\hline Primary & 22 & 12 \\
\hline Secondary & 44 & 24 \\
\hline
\end{tabular}


Citation: Kejela G, Getu S, Gebretsdik T, Wendimagegn T (2018) Prevalence of Hyperemesis Gravidarum and Associated Factors in Arba Minch General Hospital, Gamo Gofa Zone, Southern Ethiopia. Clinics Mother Child Health 15: 285. doi:10.4172/2090-7214.1000285

Page 3 of 5

\begin{tabular}{|l|l|l|}
\hline Above secondary & 77 & 42.1 \\
\hline Ethnicity & 105 & 57.4 \\
\hline Gamo & 14 & 7.7 \\
\hline Wolayta & 45 & 24.6 \\
\hline Konso & 19 & 10.4 \\
\hline Other & 19 & \multicolumn{2}{l|}{} \\
\hline Religion & \multicolumn{2}{|l|}{} \\
\hline Muslim & 6 & 3.3 \\
\hline Orthodox & 80 & 43.7 \\
\hline Protestant & 80 & 43.7 \\
\hline Others & 17 & 9.3 \\
\hline Marital condition & \multicolumn{2}{|l}{} \\
\hline Live together & 169 & 92.3 \\
\hline Not live together & 14 & 7.7 \\
\hline
\end{tabular}

Table 1: Socio-demographic characteristics of women who are admitted to gyn/ob ward in study period, AMGH, 2016.

\section{Reproductive health characteristics of respondents}

\begin{tabular}{|c|c|c|c|}
\hline S. No & Reproductive variable & Frequency & Percentage \\
\hline \multirow{4}{*}{1} & \multicolumn{3}{|l|}{ Parity } \\
\hline & Primipara & 38 & 20.8 \\
\hline & Nullipara & 34 & 18.6 \\
\hline & Multipara & 111 & 60.7 \\
\hline \multirow{4}{*}{2} & \multicolumn{3}{|l|}{ Gestational age } \\
\hline & First trimester & 29 & 15.8 \\
\hline & Second trimester & 2 & 1.1 \\
\hline & Third trimester & 152 & 83.1 \\
\hline \multirow{3}{*}{3} & \multicolumn{3}{|l|}{ Pregnancy order } \\
\hline & Single & 176 & 96.2 \\
\hline & Twin & 7 & 3.8 \\
\hline \multirow{3}{*}{4} & \multicolumn{3}{|l|}{ Time of onset of sever NVP } \\
\hline & First trimester & 130 & 80 \\
\hline & $\begin{array}{l}\text { Second trimester and } \\
\text { above }\end{array}$ & 33 & 20 \\
\hline
\end{tabular}

Table 2: Reproductive health related characteristics of pregnant women who were admitted to gyn/ob ward in study period, AMGH, 2016.

Most of the respondents were in the third trimester 152 (83.1\%) and only $2(1.1 \%)$ were in the second trimester. Primipara, nullipara and multipara account for $38(20.8 \%), 34(18.6 \%)$ and $111(60.7 \%)$ respectively (Table 2 ).

\section{Pregnancy condition of respondents}

Pregnancy condition of respondents shows that, $81.4 \%$ of the pregnancy was planned and supported and only $1.6 \%$ was planned and unsupported (Figure 1).

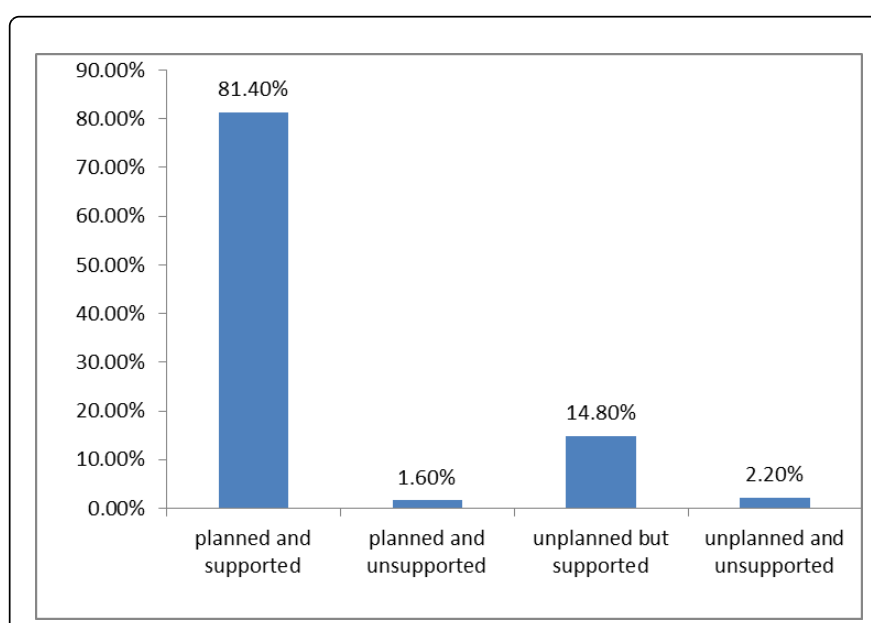

Figure 1: Pregnancy condition of pregnant women who were admitted to gyn/ob ward during the study period, AMGH, 2016.

\section{Prevalence of hyperemesis gravidarum}

Among the respondents, 15 (8.2\%) had severe NVP that required admission to a hospital. The most common triggering factors were; 7 (46.7\%) triggered by smell, $4 / 15$ (26.7\%) by taste and $4 / 15(26.6 \%)$ by both smell and test (Figure 2).

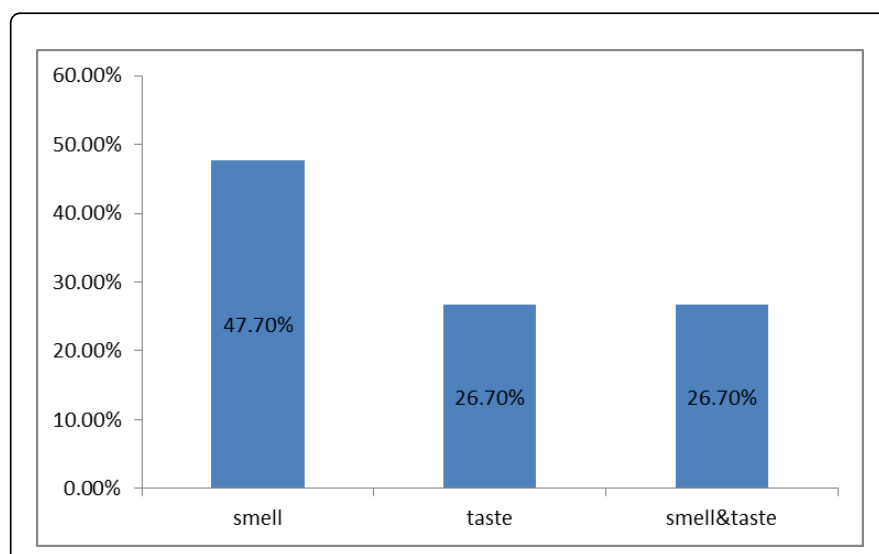

Figure 2: Triggering factors of HEG in pregnant women admitted to gyn/ob ward during the study period, AMGH, 2016.

\section{Discussion}

In this study, the prevalence of severe NVP is $8.2 \%$ which is lower than the Canadian and the Swedish reports of $19 \%$ and $17 \%$ respectively [21,22] and higher than the study done in Addis Ababa. The difference may be because of the difference in methodology and definition of severity used. In our study, severe NVP was defined as a symptom that required hospital admission while in other studies a 
NVP index scale measure was used for grading severity of nausea and vomiting [29].

In this study, the onset of symptoms in the $1^{\text {st }}$ trimester was $80 \%$ and only $20 \%$ occurred after $1^{\text {st }}$ trimester. This finding is similar with different studies reported, $90 \%$ onset of symptoms in first trimester and only $5 \%$ after 22 weeks of pregnancy $[23,24]$.

The onset of HEG is decrease with increasing gestational age. This is reasonable since the natural history of NVP is gradual improvement of symptoms as pregnancy progresses corresponding with the onset, peak and decline of maternal HCG levels. This association is well demonstrated in the present study as well.

As most reports, of the socio-demographic variables studied, the problem is high among those who were not being partnered and not being employed. This finding is different from other studies and these differences may have resulted from the difference in methodology and study population.

In similarity with other studies, HEG is higher in nullipara women, compared to multipara women. This may be due to stress and exposure to high levels of HCG for the first time [20].

\section{Limitation of the Study}

As most of the respondents were in advanced gestation during the interview, with no custom of keeping health diary or menstrual calendar, the possibility of information (recall) bias cannot be excluded.

From this cross-sectional study, it is impossible to determine causal relationships.

\section{Conclusions and Recommendations}

In this study, severe NVP accounts for $8.2 \%$, which is comparable to the currently available body of literature. Sever nausea and vomiting is higher among those not living together, in the first trimester, not employed and nullipara women. Since this study cannot show significant association, further studies with large sample size and that assess associated factors are needed.

\section{Authors' Contribution}

GK wrote the proposal, participated in data collection, analyzed the data and drafted the paper. ShG, TG and TW approved the proposal with great revisions and revised subsequent drafts of the paper. All authors read and approved the final manuscript.

\section{Competing Interest}

The authors declare that they have no competing interests.

\section{Acknowledgement}

Authors would like to thank Arba Minch University, College of medical and health sciences, school of post graduate studies for initiating them to conduct this study. Deep appreciations have gone to Arba Minch General hospital administration. Special thanks to all respondents, data collectors, supervisors and all peoples who involved in the study directly or indirectly.

\section{References}

1. O'Brien B, Evans M, White-McDonald E (2002) Isolation from "being alive": coping with severe nausea and vomiting of pregnancy. Nurs Res 51: 302-308.

2. Chou FH, Chen CH, Kuo SH, Tzeng YL (2006) Experience of Taiwanese women living with nausea and vomiting during pregnancy. J Midwifery Women's Health 51: 370-375.

3. Zhou Q, O'Brien B, Relyea J (1999) Severity of nausea and vomiting during pregnancy: What Does It Predict? Birth 26: 108-114.

4. Lee NM, Saha S (2001) Nausea and vomiting of pregnancy. Gastroenterol Clin North Am 40: 309-334.

5. Brown SS, Eisenberg L (Eds) (1995) The best intentions: unintended pregnancy and the well-being of children and families. Washington DC: National Academy Press.

6. Buckwalter J, Simpson S (2002) Psychological factors in the etiology and treatment of severe nausea and vomiting in pregnancy. Am J Obstet Gynecol 186: S210-214.

7. Chin RKH, Lao TT (1988) Low birth weight and hyperemesis gravidarum. Eur J Obstet Gynecol 28: 179-183.

8. Goodwin TM (2002) Nausea and vomiting of pregnancy: an obstetric syndrome. Am J Obstet Gynecol 186: S184-S189.

9. Allen K, Feeney E (1997) Alcohol and other drug use, abuse, and dependence. In: K Allen, J Phillips (Eds). Women's health across the lifespan: a comprehensive perspective Philadelphia, PA: Lippincott 311-332.

10. Bühling KJ (2008) Nausea and hyperemesis Gravidarum. Gynakol Geburtsmed Gynakol Endokrinol 4: 36-48.

11. Flaxman SM, Sherman PW (2000) Morning sickness: a mechanism for protecting mother and embryo. Q Rev Biol 75: 113-148.

12. Gazmararian JA, Petersen R, Jamieson DJ, Schild L, Adams MM, et al. (2002) Hospitalizations during pregnancy among managed care enrollees. Obstet Gynecol 100: 94-100.

13. Hellerstedt WL, Pirie PL, Lando HA, Curry SJ, McBride CM, et al. (1998) Differences in preconceptional and prenatal behaviours in women with intended and unintended pregnancies. Am J Public Health 88: 663-666.

14. Hod M, Orvieto R, Kaplan B, Friedman S, Ovadia J (1994) Hyperemesis gravidarum: a review. J Reprod Med 39: 605-612.

15. Jordan V, Grebe SKG, Cooke RR, Ford HC, Larsen PD, et al. (1999) Acidic isoforms of chorionic gonadotrophin in European and Samoan women are associated with hyperemesis gravidarum and may be thyrotrophic. Clin Endocrinol 50: 619-627.

16. Hod M, Orvieto R, Kaplan B, Friedman S, Ovadia J (1994) Hyperemesis Gravidarum: A Review. J Reprod Med 39: 605-612.

17. Lacasse A, Rey E, Ferreira E, Morin C, Berard A (2008) Nausea and vomiting of pregnancy: what about quality of life? BJOG 115: 1484-1493.

18. Goodwin TM (2002) Nausea and vomiting of pregnancy: An obstetric syndrome. Am J Clin Exp Obstet Gynecol 186: S184-S189.

19. Jennifer K (2010) Nausea and Vomiting in Pregnancy: Prevalence and Relationship with Psychosocial Determinants of Health; (Unpublished doctoral thesis), University of Saskatchewan, Saskatoon, Saskatchewan.

20. Jarnfelt-Samsioe A, Samsioe G, Velinder GM (1983) Nausea and vomiting in pregnancy - a contribution to its epidemiology. Gynecol Obstet Invest 16: 221-229.

21. Davis M (2004) Nausea and Vomiting of Pregnancy; An Grudzinskas JG Hyperemesisgravidarum, an evidence-based review. J Perinat Neonatal Nurs 18: 312-328.

22. Mazzotta P, Magee LA (2000) A risk-benefit assessment of pharmacological and nonpharmacological treatments for nausea and vomiting of pregnancy. Drugs 59: 781-800.

23. Miller F (2002) Nausea and vomiting in pregnancy: the problem of perception-is it really a disease? Am J Obstet Gynecol 186: S182-193.

24. Fejzo MS, Poursharif B, Korst LM, Munch S, MacGibbon KW, et al. (2009) Symptoms and Pregnancy Outcomes Associated with Extreme 
Citation: Kejela G, Getu S, Gebretsdik T, Wendimagegn T (2018) Prevalence of Hyperemesis Gravidarum and Associated Factors in Arba Minch General Hospital, Gamo Gofa Zone, Southern Ethiopia. Clinics Mother Child Health 15: 285. doi:10.4172/2090-7214.1000285

Page 5 of 5

Weight Loss among Women with Hyperemesis Gravidarum. J Womens Health (Larchmt) 18: 1981-1987.

25. Woolhouse M (2006) Complementary medicine for pregnancy complications. Aust Fam Physician 35: 695.

26. Zuckerman B, Amaro H, Bauchner H, Cabral H (1989) Depression symptoms during pregnancy: relationship to poor health behaviors. Am J Obstet Gynecol 160: 1107-1111.
27. Lacroix R, Eason E, Melzack R (2000) Nausea and vomiting during pregnancy: a prospective study of its frequency, intensity and patterns of change. Am J Obstet Gynecol 182: 931-937.

28. Kuma T, Yusuf L, Negash S (2013) Assessment of nausea and vomiting of pregnancy on antenatal clients of Addis Ababa. Ethiop J Health Dev 27.

29. Arbaminch town Health office (2011) Report of the district Health department. 